\title{
ANALYSIS OF INFLUENCE OF NONSTATIONARY POWER OF HEATING RADIATOR ON HUMAN COMFORT LEVEL
}

\author{
Egils Dzelzitis, Sandra Sidenko \\ Riga Technical University, Latvia \\ egils.dzelzitis@rtu.lv, sandysid@inbox.lv
}

\begin{abstract}
Total energy consumption of buildings and structures in the construction sector today accounts for $41 \%$ of the total European Union (EU) energy consumption. For heating and air conditioning are used $85 \%$ of total energy consumption. Therefore, one of the main ways to increasing of the heat power devices efficiency in the future - improvement of the heat exchanging equipment, which can be realized through the introduction of effective heat transferring intensifications methods. Special attention now is paid to studies of pulsating flow influence on heat transferring. Such unsteady flows can be created artificially, or may appear during the operation of the thermal energy equipment, and can be accompanied by increasing and decreasing of the heat transferring intensity. However, the influence of such a regime on a human comfort level is not enough studied. The purpose of this work is to investigate the effect of the pulsating mass flow rate of the circulating media on the thermal power of a panel heating radiator and to analyze the effect of thermal pulsations on the human comfort level. At the first stage, a type P11 steel panel radiator, with overall dimensions of $600 \times 800 \mathrm{~mm}$ and operating pressure up to $10 \mathrm{Bar}$, was studied. The circulating media in the radiator is water. The average mass flow rate of the circulating media is $M=0.1 \mathrm{~kg} \cdot \mathrm{s}^{-1}$, the temperature head is $70^{\circ} \mathrm{C}$, the pulsation frequency range of the circulating media is from 0 to $5 \mathrm{HZ}$. At the second stage, the radiator was installed in a model of the room in which people were located, where the influence of thermal pulsations on the level of human comfort was studied. Numerical modeling was carried out with using of the CAD/CFD complex of Solid Works/Flow Simulation software. The complete system of Navier-Stokes equations and the energy equation were solved using the $k-\varepsilon$ turbulence model in a non-stationary formulation of the problem. Results of the numerical calculations showed that the periodic pulsating mass flow rate of the circulating media in the heating radiator, compared with the stationary mode, leads to an increase in the average heat flux of the radiator during operation by approximately $25 \%$. And, as a result, it leads to uncomfortable conditions in the room where people are located.
\end{abstract}

Keywords: pulsating flow, heat transfer, Navier-Stokes equations, PMV, PPD, operative temperature.

\section{Introduction}

The building sector is the main energy consumer in Europe. Buildings account for $41 \%$ of all energy consumed. $85 \%$ of this energy is spent for heating and cooling of premises, and $15 \%$ is spent in the form of electricity. Generally buildings consume $35 \%$ of primary energy to achieve comfortable indoor temperatures and $6 \%$ of electricity [1].

Therefore, the main objective of the design and construction of energy-efficient buildings is the more efficient use of energy resources which are spent on the building's energy supply. This is achieved through the use of innovative solutions that are technically feasible, economically justified, and acceptable from an environmental and social point of view, and at the same time do not change the usual way of people's life [2-7].

In heat supply systems of buildings and structures, the heat exchange equipment is mainly the main part and largely determines the general technical and economic indicators. And in future, one of the main ways to increase the efficiency of heat power devices is improvement of the heat exchange equipment, which can be realized by introducing effective methods of intensifying heat transfer [8-9].

By heat transfer intensifying, the amount of heat transferred through a unit of the heat transfer surface increases, and a more favorable ratio between the transferred amount of heat and pumping of the heating media is achieved [10-14].

Currently, special attention is paid to studies of the influence of the pulsating flow on heat transfer. Such unsteady flows can be created artificially, or may arise during the operation of thermal equipment.

Experimental studies of unsteady flows in channels carried out in [15-20], and in room heating radiators as well, showed that flow pulsations can significantly affect hydrodynamics and heat transfer. And such non-stationary processes can be accompanied by both an increase and a decrease in the intensity of the heat transfer. 
However, the question of the effectiveness of this method remains open, because of little knowledge on the course of such processes. It is also not clear how the considered non-stationary processes that occur in the channels and room heating radiators in which people are located will affect the comfort level.

The aim of this work is to investigate the effect of the pulsating mass flow rate of the circulating media on the thermal power of a panel heating radiator and to analyze the effect of thermal pulsations on the human comfort level.

\section{Materials and methods}

At the first stage, to verify the accuracy of solving the problem, a type P11 panel radiator was studied. To do this, in the SolidWorks CAD software, a geometric radiator model with overall dimensions of $600 x 800 \mathrm{~mm}$ was built. 3D of the radiator is shown in Fig. 1.

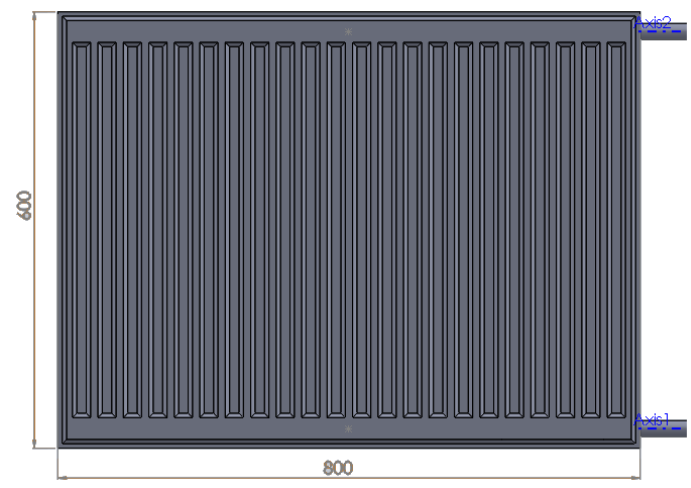

Fig. 1. 3D model of the radiator

The radiator is designed for the heated area up to $10 \mathrm{~m}^{2}$. Inner diameter of the inlet and outlet water pipes (pos.8) is $20 \mathrm{~mm}$. As a material in Flow Simulation software stainless steel was chosen: density $-7900 \mathrm{~kg} \cdot \mathrm{m}^{-3}$, thermal conductivity $-16.3 \mathrm{~W} \cdot(\mathrm{m} \cdot \mathrm{K})^{-1}$, specific heat $-500 \mathrm{~J} \cdot(\mathrm{kg} \cdot \mathrm{K})^{-1}$.

According to the methodology of thermal tests of radiators with water, for the stationary case of supply of a media, as the boundary conditions for numerical calculation it was accepted: barometric pressure $P=1013.3 \mathrm{kPa}$, mass flow rate $M=0.1 \mathrm{~kg} \cdot \mathrm{s}^{-1}$ and the estimated temperature head $T=70^{\circ} \mathrm{C}$.

To study the effect of flow pulsations on heat transfer, a model of a periodically pulsating mass flow rate $\mathrm{M}(\mathrm{t})$ of a media in a radiator with a sinusoidal pulse is used and described by equation (1):

$$
M(t)=0.4(1+A \sin (2 \pi f t))
$$

where $t$-time, s;

$M$ - mass flow rate, $\mathrm{kg} \cdot \mathrm{s}^{-1}$

$A$ - amplitude of the pulsations, $\mathrm{A}=1$;

$f$ - pulsating frequency, $f=0-5 \mathrm{~Hz}$.

Water is considered as a heat carrier in a heating system and radiator. For the case of a stationary flow, the velocity of water in the inlet is $V=0.4 \mathrm{~m} \cdot \mathrm{s}^{-1}$ (top flow rate) with a pressure $P=5 \mathrm{bar}$. Inlet flow temperature is $80^{\circ} \mathrm{C}$, outlet is $60^{\circ} \mathrm{C}$.

Then, at the second stage, a geometric simulation three-dimensional model of the room in the SolidWorks CAD software was built. Due to the complexity of the numerical solution of the problem, the overall dimensions of the room were selected relatively small. Room area was set $S=3000 \times 3000 \mathrm{~mm}$, ceiling height $2500 \mathrm{~mm}$. Calculation of the thermal regime is planned with taking into account the thermal conductivity of the building structures, and in this case the geometric model contains walls, ceiling, floor, a window and door. 3D model of the office room is shown in Fig. 2.

All necessary initial and boundary conditions were set in the Flow Simulation part of the SolidWorks software package. It is assumed that the walls pos. 1 have brickwork with the following physical properties: density $-1700 \mathrm{~kg} \cdot \mathrm{m}^{-3}$, thermal conductivity $-0.62 \mathrm{~W} \cdot(\mathrm{m} \cdot \mathrm{K})^{-1}$, specific heat $800 \mathrm{~J} \cdot(\mathrm{kg} \cdot \mathrm{K})^{-1}$. The window (pos.6) and door (pos.5) were considered as a double-glazed window, 
with the following physical properties: density - $2500 \mathrm{~kg} \cdot \mathrm{m}^{-3}$, thermal conductivity $0.699 \mathrm{~W} \cdot(\mathrm{m} \cdot \mathrm{K})^{-1}$, specific heat $-837 \mathrm{~J} \cdot(\mathrm{kg} \cdot \mathrm{K})^{-1}$. Room's air temperature is $15^{\circ} \mathrm{C}$.

Intake of fresh air into the room is carried out through the ventilation inlet hole pos. 4 , which is located in the wall and has connection to the street air. Overall dimensions of the ventilation inlet are $170 \times 170 \mathrm{~mm}$, inlet flow rate $0,006 \mathrm{~m}^{3} \cdot \mathrm{s}^{-1}$, incoming air temperature $15^{\circ} \mathrm{C}$.

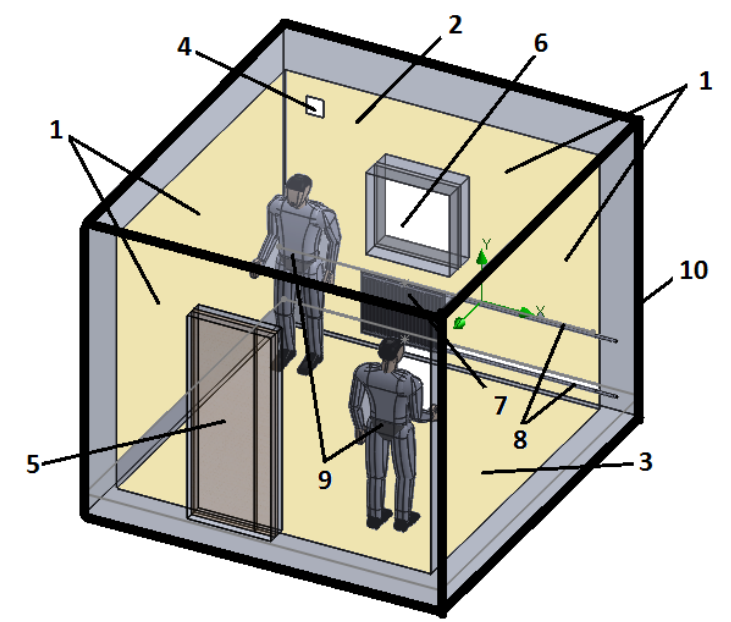

Fig. 2. 3D model of the room: 1 - walls; 2 - ceiling; 3 - floor 4 - ventilation inlet;

5 - door; 6 - window; 7 - radiator; 8 - pipes; 9 - humans; 10 - calculated domain

For heating of the room, a type P11 steel panel radiator (7) is used, the inner diameter of the inlet and outlet connecting pipes (8) is $20 \mathrm{~mm}$.

Here, in order to determine the effect of pulsations of the heat flux in the room on the people's comfort level in it, two cases were investigated: when the mass flow rate of the heat carrier into the heating radiator was supplied at a frequency $f=0 \mathrm{~Hz}$ and $f=5 \mathrm{~Hz}$.

\section{Mathematical model}

The non-stationary Navier-Stokes energy equation (the first law of thermodynamics) and the equation of state are used for mathematical modeling of the motion of the medium and heat exchange. For turbulent flows the initial equations are averaged by the Reynolds method and additional stresses due to turbulent parameter pulsations are taken into account. The obtained unclosed system of equations is closed with the help of additional equations for the kinetic energy of the turbulence $\mathrm{k}$ and dissipation of the turbulence energy $\varepsilon$ in accordance with the known $\mathrm{k}-\varepsilon$ turbulence model [21]. The system of equations of conservation of momentum (4), mass (5) and energy (6), describing turbulent, laminar and transient flows of compressible fluid with heat exchange, can be represented as

$$
\begin{gathered}
\frac{\partial \rho u_{i}}{\partial t}+\frac{\partial}{\partial x_{j}}\left(\rho u_{i} u_{j}-\tau_{i j}\right)+\frac{\partial P}{\partial x_{i}}=F_{i} \\
\frac{\partial \rho}{\partial t}+\frac{\partial}{\partial x_{j}}\left(\rho u_{j}\right)=0 \\
\frac{\partial(\rho E)}{\partial t}+\frac{\partial}{\partial x_{i}}\left((\rho E+P) u_{i}+q_{i}-\tau_{i j} u_{j}\right)=F_{i} u_{i}+Q_{H}
\end{gathered}
$$

Two additional transport equations are used to describe the turbulent kinetic energy $k$ and dissipation $\varepsilon$ :

$$
\begin{aligned}
& \frac{\partial \rho k}{\partial t}+\frac{\partial}{\partial x_{i}}\left(\rho u_{i} k\right)=\frac{\partial}{\partial x_{i}}\left(\left(\mu_{l}+\frac{\mu_{t}}{\sigma_{k}}\right) \frac{\partial k}{\partial x_{i}}\right)+S_{k} \\
& \frac{\partial \rho \varepsilon}{\partial t}+\frac{\partial}{\partial x_{i}}\left(\rho u_{i} \varepsilon\right)=\frac{\partial}{\partial x_{i}}\left(\left(\mu_{l}+\frac{\mu_{t}}{\sigma_{\varepsilon}}\right) \frac{\partial \varepsilon}{\partial x_{i}}\right)+S_{\varepsilon}
\end{aligned}
$$


where the source terms $S_{k}(7)$ and are defined $S \varepsilon(8)$ as:

$$
\begin{gathered}
S_{k}=\tau^{R}{ }_{i j} \frac{\partial u_{i}}{\partial x_{j}}-\rho \varepsilon+\mu_{t} P_{B} \\
S_{\varepsilon}=C_{\varepsilon 1} \frac{\varepsilon}{k}\left(f_{1} \tau^{R}{ }_{i j} \frac{\partial u_{i}}{\partial x_{j}}+\mu_{t} C_{B} P_{B}\right)-C_{\varepsilon 2} f_{2} \frac{\rho \varepsilon^{2}}{k}
\end{gathered}
$$

Following Boussinesq assumption, the Reynolds-stress tensor (9) has the following form:

$$
\tau^{R}{ }_{i j}=\mu_{t}\left(\frac{\partial u_{i}}{\partial x_{i}}+\frac{\partial u_{j}}{\partial x_{i}}-\frac{2}{3} \frac{\partial u_{l}}{\partial x_{l}} \delta_{i j}\right)-\frac{2}{3} \rho k \delta_{i j}
$$

The diffusive heat flux (10) is defined as:

$$
q_{i}=-\left(\frac{\mu_{l}}{\operatorname{Pr}}+\frac{\mu_{t}}{\sigma_{c}}\right) C_{P} \frac{\partial T}{\partial x_{i}}
$$

Upon analyzing the conjugate heat exchange between the flow and the solid, the heat transfer in the solid is simulated by the known heat transfer equation (11):

$$
\frac{\partial \rho e}{\partial t}=\frac{\partial}{\partial x_{i}}\left[\lambda_{s} \frac{\partial T}{\partial x_{i}}\right]+Q_{H},
$$

where $u_{i j}$ - fluid velocity is a function of four independent variables $x, y, z, t$;

$P$ - fluid pressure is a function of four independent variables $x, y, z, t$;

$\rho$ - fluid density;

$F_{i}$ - total force acting on the mass unit;

$E$ - total energy of the fluid mass unit;

$Q_{H}$ - heat source per volume unit;

$\tau_{i j}$ - viscous shear stress tensor;

$i=x, y, z ; j=x, y, z$ - summing is made by subscripts;

$\mu_{l}, \mu_{t}-$ dynamic viscosity coefficient, turbulent viscosity coefficient;

$\sigma_{k}, \sigma_{\varepsilon}$ - empirical constants;

$\tau_{i j}{ }^{R}$ - stress tensor in Reynolds model;

$g_{i}$ - components of gravitational acceleration in direction $x_{i}$;

$\mathrm{Pr}$ - Prandtl number;

$C_{P}$ - specific thermal capacity at constant pressure;

$\delta_{i j}-$ Kronecker symbol;

$e$ - specific heat;

$T$ - temperature;

$\lambda_{s}-$ solid thermal conductivity.

The above equations (2)-(11) are highly general. Herein after, the authors concretize the constant values, as well as the dependent and independent variables to solve the particular problems. Equations (2)-(11) are solved numerically using the CFD software Flow Simulation [16]. Initial and boundary conditions for specific tasks are set in the Flow Simulation software in the volume and on the corresponding surfaces of the three-dimensional design model created in the CAD (computer-aided design) SolidWorks software.

For numerical solving the system of equations (2)-(11), the Flow Simulation software uses the finite volume method with an adaptive rectangular grid. In the process of calculation the initial grid of finite volumes in the computational area is crushed automatically, or according to the given rule in areas of assumed large gradients of each of the dependent variables, or in areas of significant change in the curvature of the solid surfaces. All basic variables are referred to mass centers of control volumes. These cell-centered values are used for approximations. The integral conservation laws may be represented in the form of the cell volume and surface integral equation (12)-(13) [21]:

$$
\frac{\partial}{\partial t} \int U d v+\oint F d s=\int Q d v
$$


are replaced by the discrete form:

$$
\frac{\partial}{\partial t}(U \cdot V)+\sum_{\text {cell }} F \cdot S=Q \cdot V
$$

where $F$-fluxes;

$U$ - vector of physical parameters;

$V$ - cell volume;

$S$ - cell surface area;

$Q$ - mass forces.

For reducing the numerical solution time in the places where high gradients are assumed, of course, the volumetric grid was crushed locally. This applies to the area of the radiator, vent, and areas where people are present.Note that in accordance with the calculation methodology any stationary problem is initially solved as non-stationary. The solution is considered to be found after its settings of time.

\section{Processing of the experimental data}

At the first stage, a numerical thermal calculation of a P11 type panel radiator was carried out for the stationary and frequency modes of the media supply.The processing of the obtained experimental data on the heat calculation of the radiator was carried out according to the main calculated dependences and taking into account the results of numerical calculation.

The actual temperature head $T_{\text {fact }},{ }^{\circ} \mathrm{C}(14)$ was determined:

$$
T_{\text {fact }}=\frac{t_{n}-t_{k}}{2}-t_{p}
$$

where $t_{n}, t_{k}$ - initial and final temperature of the media in the radiator $\left({ }^{\circ} \mathrm{C}\right)$; $\left({ }^{\circ} \mathrm{C}\right)$.

$t_{p}$ - design room temperature, taken equal to the calculation of the room temperature

And also the heat flux $Q(W)$ under the condition different from normalized according to equation (15):

$$
Q=K_{h y} \cdot 70 \cdot F \cdot \varphi_{1} \cdot \varphi_{2} \cdot b \cdot p
$$

where $K_{h y}$ - radiator heat transfer coefficient, W;

$\varphi_{1}-$ coefficient taking into account the change in the heat flux in the radiator, depending on the temperature head;

$\varphi_{2}$ - coefficient taking into account the change in the heat flux in the radiator, depending on the calculated mass flow rate and the media motion scheme;

$b$ - coefficient taking into account the calculated atmospheric pressure;

$p$ - coefficient taking into account the dependence of the heat flux and heat transfer coefficient of the radiator on its length;

$F$ - area of the outer heat-transfer surface of the radiator, $\mathrm{m}^{2}$.

On the second stage by using the HVAC Flow Simulation module of the SolidWorks software package parameters of the thermal sensation, the discomfort level of people exposed to the environment was predicted. Results of the numerical calculations generalizing a series of computer experiments were determined according to the following equations [3; 21]: PPD, PMV and Operative Temperature. PPD (predicted percentage of dissatisfied) is an indicator that sets the predicted percentage of unsatisfied with the quality of the microclimate for people, for whom it is too warm or cold. Unsatisfied microclimate means for those people, who will evaluate the environment as "hot", "warm", "cool" or "cold". This characteristic is probabilistic in nature (can take values from 5 to 99, (9) \%). PPD (16) can be derived from the Fanger comfort index (PMV) parameter:

$$
P P D=100-95 \exp \left(-0.03353 P M V^{4}-0.2179 P M V^{2}\right)
$$

where PMV - Function Predicted Mean Vote calculated by the equation according to literature $[3 ; 21]$. 
Operative temperature is the homogeneous temperature of the visually black environment, in which a person receives the same amount of the heat through radiation in conjunction with convection, as if he was in an environment with an inhomogeneous temperature (17)

$$
T_{c}=\frac{T_{r}+T_{a} \sqrt{10 v}}{1+\sqrt{10 v}},
$$

Where $T_{r}$ - average radiation temperature, ${ }^{\circ} \mathrm{C}$;

$T_{a}$ - air temperature, ${ }^{\circ} \mathrm{C}$;

$v$ - air velocity, $\mathrm{m} \cdot \mathrm{s}^{-1}$.

\section{Results and discussion}

The results of numerical calculations showed that the periodic fluctuations in the mass flow rate $M(t)$ of the circulating media supplied to the heating radiator (Fig. 2) lead to periodic fluctuations in the temperature head (Fig. 3). Figure 3 shows the time dependence of the mass flow rate of the circulating media for the pulsation frequency $f=3 \mathrm{~Hz}$. Here, the amplitude and frequency of oscillations are described by equation (1) and the average mass flow rate is equal to the value set when solving the stationary problem $M=0.1 \mathrm{~kg} \cdot \mathrm{s}^{-1}$.

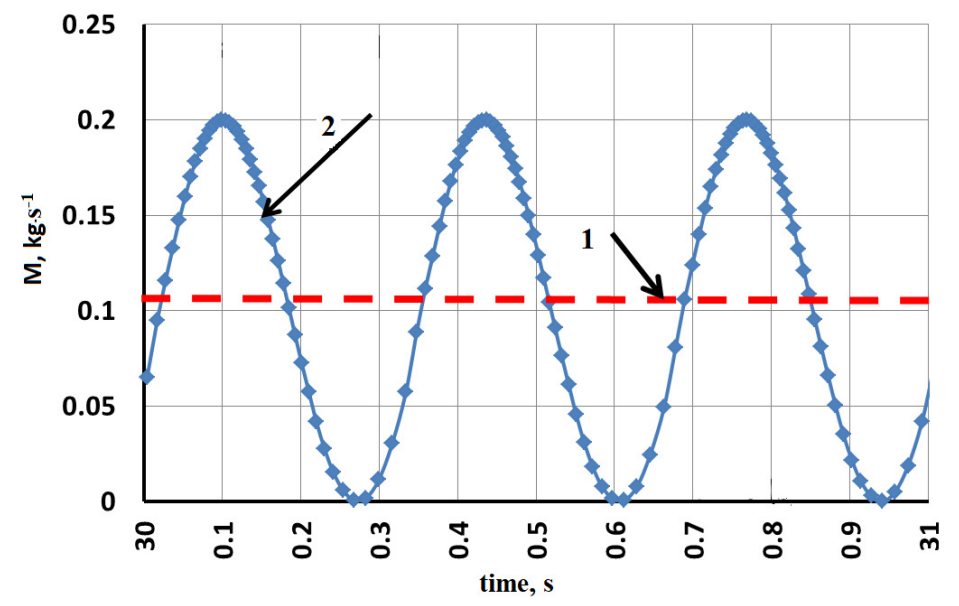

Fig. 3. Dependence of the mass flow rate $M(t)$ on time for $\mathbf{f}=3 \mathrm{~Hz}$ :

Line 1 - for the stationary case, line 2 - according to the equation (1)

Figure 4 shows the variations in the temperature head over time for the pulsation frequency of the mass flow rate $f=3 \mathrm{~Hz}$. Here it can be observed that the maximum temperature head in the pulsating mode is approximately equal to the value for the stationary case $T_{\text {fact }}=70^{\circ} \mathrm{C}$. The temperature drop in the pulsation mode occurs at the time when the mass flow reaches a value of $0.5 M(t)$ from the average mass flow and reaches its minimum when $M(t) \rightarrow 0$. In this case, the temperature difference in relation to $T_{\text {fact }}$ is about $20 \%$.

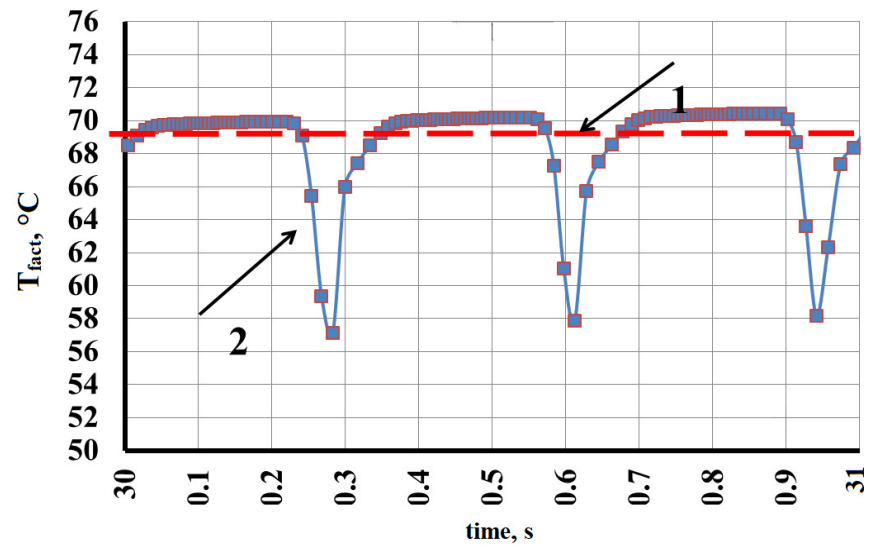

Fig. 4. Fluctuations in temperature head for $\mathbf{f}=3 \mathbf{H z}$ :

Line 1 is for a stationary case, line 2 is a pulsating mode 
This fact significantly affects the value of the heat flow of the heater (Fig. 5). Figure 4 shows the dependence of the heat flux on time, line 1 - corresponds to the nominal heat flux of the radiator under normalized conditions and is $Q=1263$ Watt (according to declared by the manufacturers). According to the results of numerical calculation, the heat flux for the stationary case is $Q=1263$ Watt, which assumes satisfactory convergence of the result with the manufacturers' declared data. Line 2 corresponds to the pulsating mass flow rate of the media. Since the heat flux depends on the mass flow rate of the media, respectively, when the maximum mass flow rate of the coolant is reached, the value of the heat flux also reaches its maximum. A similar picture is observed also at minimum values. Line 3 - corresponds to the average value of the heat flux for the pulsation frequency of the mass flow $f=3 \mathrm{~Hz}$. As it can be seen, comparing with the stationary mode, the average heat flux of the radiator increases by approximately $22 \%$.

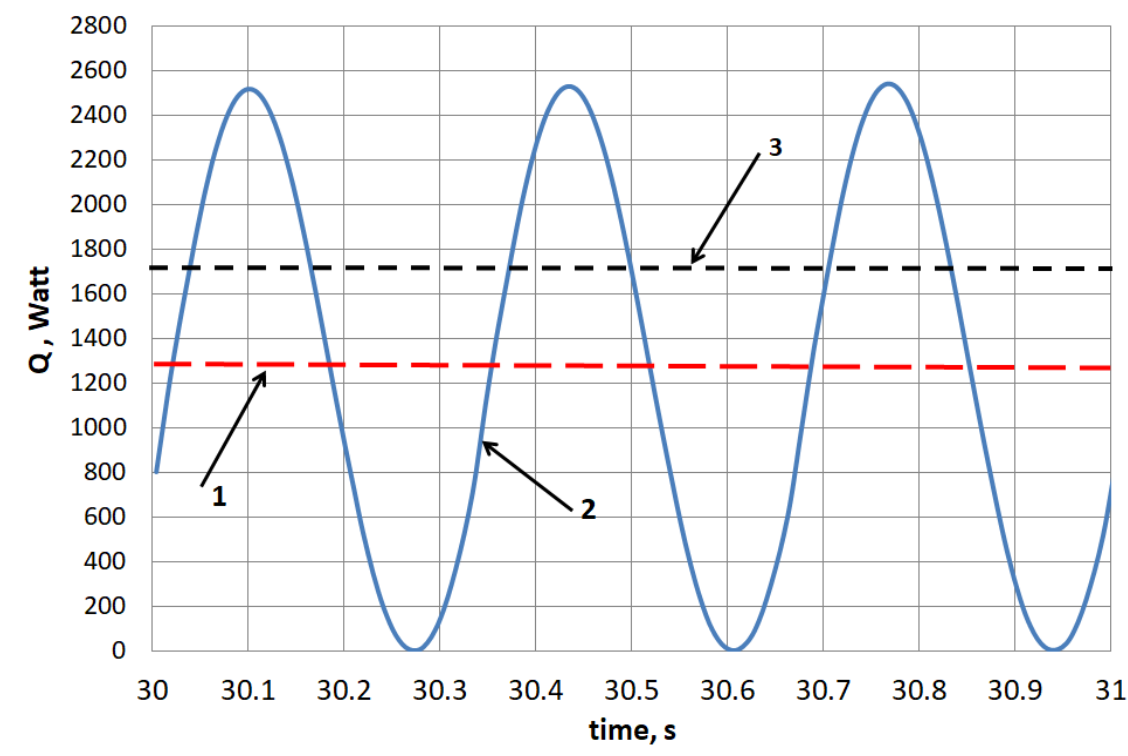

Fig. 5. Dependence of the heat flux on time for $f=3 \mathrm{~Hz}$ : 1 - nominal heat flux and the result of the numerical solution, 2 - pulsating mode, 3 - average value of the heat flux at $f=3 \mathrm{~Hz}$

The results of numerical calculations for the pulsation frequencies of the mass flow rate $f=1$ $5 \mathrm{~Hz}$ showed that with an increase in the pulsation frequency, the average heat flux increases accordingly and at $f=5 \mathrm{~Hz}$ it reaches $25 \%$ of the nominal.

Further, the work carried out numerical studies of the influence of pulsations of the heat flux on the people's comfort level in the room. For this purpose, two tasks were solved: when the circulating media with a constant mass flow rate and pulsating at $f=5 \mathrm{~Hz}$ was supplied to the heating radiator, which is installed in the room model.

Further, this study investigated changing the operative temperature in the radiator region, according to equation (17). Temperature parameters were taken at given points with the corresponding coordinates in the space $x, y, z$. The area under consideration was conditionally divided into three zones: zone 1 - the area where pipes for inlet and outlet of the heating fluid are located, zone 2 - the radiator area, zone 3 - the area in which persons are located, there is no heating device, and there is a ventilation hole on the top of the wall.

The results showed that in the first zone with respect to the stationary regime, pulsations of the fluid flow do not significantly expose on the operating temperature $T{ }^{\circ} \mathrm{C}$. The second zone is characterized by increasing in the operating temperature approximately $20 \%$, due to the pulsating changing in the heat power of the radiator. Comparing with the second zone, in the third zone decreasing of the operating temperature by an average $20-25 \%$ is observed.

The human self-sense is determined by the heat balance in his body. In the numerical calculation process environmental parameters were determined, such as the average radiation temperature $T r$, as well as the temperature $T a$, the relative velocity v, and the air humidity. This allows us to predict the thermal sensations Predicted Mean Vote (PMV average predicted rating) of the people in the room, 
according to the Fanger Comfort Index [3;21]. Visualized picture of the Predicted Mean Vote in the room is shown in Fig. 6.

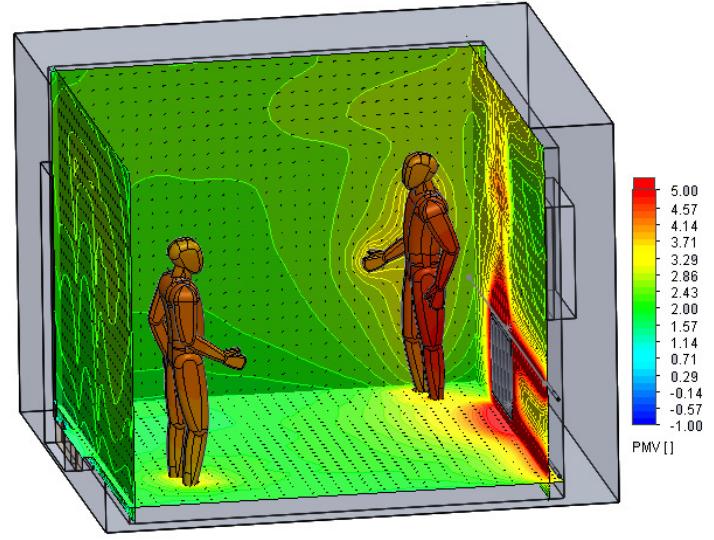

Fig. 6. Thermal feelings for the Predicted Mean Vote

The figure shows that there is a maximum value of the PMV +5 and it is outside of the calibrated scale from -3 to +3 , that is, the condition of a person near the radiator can be assessed as "very hot". For the opposite person from the zone between "warm" and "hot", that is, from +2 to +3 .

In the case of unsteady flow regime of the fluid, the PMV value of the person located near the radiator reaches up to +6 . Due to increasing in the heat output of the radiator.

Predicted percentage of unsatisfied (PPD) people indoors is the proportion of people with discomfort conditions in a given environment. This characteristic is probabilistic (with values from 5 to $99,(9) \%$ ) and is calculated according to equation (14). Visualization of the Predicted Percent Dissatisfied (PPD) of the environment is shown in Fig. 7.

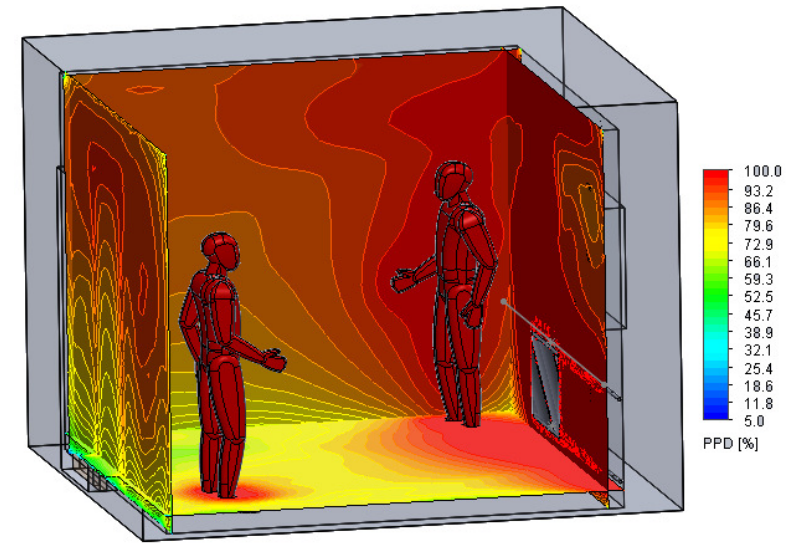

Fig. 7. Predicted percentage of unsatisfied

As we can see, almost the entire room is uncomfortable and both people who are in it are not satisfied with the quality of their environment

This is explained by the high temperature of the supply of the circulating media and the influence of pulsations of the media in the radiator, leading to an increase in its thermal power. And as a consequence, of the deterioration of climatic conditions affecting the people comfort level in the considered model of the room.

\section{Conclusions}

1. In this work, many significant design and operational features that affect the level of comfort in the room were not taken into account. The main objective of this work was to identify the effect of the periodically pulsating flow of the fluid on the body power of the radiator, and as a result on the comfort conditions of the people in this room. 
2. It was revealed that the periodic pulsating mass flow rate in the heating radiator, in comparison with the stationary mode, leads to an increase in the average heat flow during operation. With an increase in the pulsation frequency, the average value of the heat flux in comparison with the stationary regime of supply of the heating media can be increased by approximately $25 \%$. This effect can allow to reduce temperature of the circulating media, or to install heating radiators with lower thermal power to create normal conditions of comfort.

3. The room model in the considered operating regime is not comfortable; this conclusion is based on several criteria identified in the process of numerical calculations. The main area of discomfort is the area near the radiator. This applies to both regimes under consideration, while in the pulsating regime of operation of the radiator, the discomfort zone increases by approximately $10 \%$.

4. Cold air entering through the ventilation hole is ineffective. Therefore, in order to optimize further work, it will be necessary to take into account additional optimization tasks associated with the installation of additional ventilation holes or air conditioners, or other means.

\section{Acknowledgements}

This research/publication was supported by the Riga Technical University Doctoral Grant programme.

\section{References}

[1] Communication from the Commission to the European Parliament, the Council, the European economic and social committee and the committee of the regions COM (2011) 109 of "Energy Efficiency Plan 2011" [online][08.03.2011] Available at: http://eurlex.europa.eu/LexUriServ/LexUri Serv.do?uri = COM:2011:0109:FIN:EN:PDF

[2] "The impact of building automation and control functios on the energy effi ciency of buildings". Document Nr. CM110854en_02 2008. Siemens Switzerland Ltd.

[3] "The business case for green building". 2013. World Green Building Council. European Standard EN 15232. "Energy Performance of Buildings. Impact of Building Automation, Controls and Building Management" [online][22.03.2020] Available at: http://www.cres.gr/greenbuilding/PDF/prend. $\mathrm{s}^{-1} \mathrm{e}$ t4/WI_22_TCapproval_version_prEN_15232_Integrated_Building_Automation_Systems.pdf

[4] Borodinecs A., Prozuments A., Zajacs A., Zemitis, J.Retrofitting of fire stations in cold climate regions. Magazine of Civil Engineering, 90(6), 2019, pp. 85-92. DOI: 10.18720/MCE.90.8

[5] Sergeev V. V., Petrichenko M. R., Nemova D. V., Kotov E. V., Tarasova D. S., Nefedova A. V., Borodinecs A. B. The building extension with energy efficiency light-weight building walls. Magazine of Civil Engineering, 84(8), 2018, pp. 67-74. DOI: 10.18720/MCE.84.7

[6] Baranova D., Sovetnikov D., Borodinecs A. The extensive analysis of building energy performance across the baltic sea region. Science and Technology for the Built Environment, 24(9), 2018, pp. 982-993. DOI: 10.1080/23744731.2018.1465753

[7] Zemite L., Gerhards J. Reliability evaluation of distribution systems. 9th International Conference on Electrical and Control Technologies, ECT 2014, pp. 94-99.

[8] Li R., Odintsov A., Sidenko S. Optmizing heat transfering surface shape of brazed plate heatexchanger, Engineering for rural development. Jelgava, 22.-24.05.2019, pp. 726-732. DOI: 10.22616/ERDev2019.18.N040

[9] Rostislav Li1, Aleksandr Odintsov1, Sandra Sidenko// Experimental research in brazed plate-type heat exchangers, Engineering for rural development. Jelgava, 22.-24.05.2019, pp. 733-738. DOI: 10.22616/ERDev2019.18.N046

[10] Mahmood G. I., Ligrani P. M. Heat transfer in a dimpled channel: Combined influences of aspect ratio, temperature ratio, Reynolds number, and flow Structure. Intern. J. of Heat and Mass Transfer, 2002, vol. 45, iss. 10, pp. 2011-2020.

[11] Kiselev N.A., Burtsev S.A., Strongin M.M. A procedure for determining the heat transfer coefficients of surfaces with regular relief. Measurement Techniques, 2015, vol. 58, no. 9, pp. 1016-1022. DOI: $10.1007 \cdot \mathrm{s}^{-1} 11018-015-0835-7$ 
[12] Sidenko N., Dzelzitis E. "The method of numerical modeling of hydrodynamics and heat exchange in a channel with discrete roughness” International Scientific Journal „Mathematical Modeling” year II, ISSUE2/2018 ISSN (print) 2535-0986, ISSN (WEB) 2603-2929, pp. 61-65

[13] Dzelzitis E., Sidenko N. Numerical simulation of heat exchange in discrete-rough channels at flow superimposed oscillations. Engineering for rural development. Jelgava, 22.-24.05.2019. pp. 1155-1161. DOI: 10.22616/ERDev2019.18.N203

[14]Leontiev A.I., Dilevskaya E.V., Vinogradov Yu.A., Yermolaev I.K., Strongin M.M., Bednov S.M., Golikov A.N. Effect of vortex flows at surface with hollow-type relief on heat transfer coefficients and equilibrium temperature in supersonic flow. Experimental Thermal and Fluid Science, 2002, vol. 26, iss. 5, pp. 487-497. DOI: $10.1016 \cdot \mathrm{s}^{-1} 0894-1777(02) 00157-7$

[15] Laptev A.G., Nikolaev N.A., Basharov M.M. Intensification methods and simulation of the heat and mass transferring processes. Reference guide.- M.: "Heating engineer", 2011, 335 p.

[16] Galicejskij B.M. Thermal and hydrodynamic processes in oscillating flows / B.M. Galicejskij, YU.A. Ryzhov, E.V. YAkush. M., "Engineering", 1977. 256 p.

[17] Rony R.U., Hasan M.N., Laskar M.A.R. Heat Transfer of Pulsating Turbulent Flow in Pipes. European Journal of Advances in Engineering and Technology, 5(8), 2018, pp. 511-516.

[18] M. Embaye, R. K. Al-Dadah \& S. Mahmoud. The effect of flow pulsation on the heating performance of panel radiators in central heating systems: CFD analysis.

[19] Advanced Computational Methods and Experiments in Heat Transfer XIIIWIT Transactions on Engineering Sciences, Vol 83, (C) 2014 WIT Press ISSN 1743-3533. DOI: 10.2495/HT140031

[20] Myhren J. A., Holmberg S., Flow patterns and thermal comfort in a room with panel, floor and wall heating. Energy and Buildings, 40, 2008, pp. 524-536.

[21] Alyamovsky A.A. SolidWorks Simulation. // BHV- Petersburg, Saint-Petersburg, 2012. 448 p. ISBN 978-5-9775-0763-9. 